\title{
Hardening of FeCrMoWCBSi amorphous electrospark coatings with tungsten carbide
}

\author{
A. A. Burkov, M. A. Kulik ${ }^{\dagger}$ \\ †marijka80@mail.ru \\ Institute of Materials Science, Khabarovsk Scientific Centre, FEB RAS, Khabarovsk, 680042, Russia
}

\begin{abstract}
A new direction in the development of metal-matrix coatings are composites based on an amorphous matrix with reinforcing ceramic additives. In this work, composite coatings were prepared by electrospark treatment of AISI 1045 in a mixture of iron granules with a multicomponent composition CrMoWCBSi and the addition of tungsten carbide powder. According to $\mathrm{X}$-ray analysis, with an increase in the concentration of WC in the mixture of granules up to $1.2 \mathrm{vol} . \%$, the content of the WC phase in the coating composition increased. In addition, the X-ray analysis showed metallic tungsten, which is a product of the partial dissolution of WC particles in the iron melt. In the microstructure of the coatings, inclusions of tungsten carbide with a diameter of $1.8 \pm 0.9 \mu \mathrm{m}$ were observed. The oxidation resistance of the coatings at a temperature of $700^{\circ} \mathrm{C}$ decreased monotonically with an increase of WC additive in the mixture of granules. The microhardness of the coatings with tungsten carbide was in the range from 814 to $1118 \mathrm{HV}$, which is higher compared to a completely amorphous sample (743 HV). The average values of the coating friction coefficient with WC ranged from 0.60 to 0.67 , which is $30 \%$ lower than that of an amorphous coating. The wear rate of coatings with tungsten carbide was in the range of $0.5-1.1 \times 10^{-5} \mathrm{~mm}^{3} / \mathrm{Nm}$, which is lower than that of the sample without WC $\left(1.8 \times 10^{-5} \mathrm{~mm}^{3} / \mathrm{Nm}\right)$. The optimal value of the addition of WC powder in the mixture of granules during the deposition of the coatings for tribotechnical applications is 1.2 vol.\%. Thus, the use of amorphous coatings reinforced with tungsten carbide makes it possible to reduce the wear of steel 45 by up to 8 times.
\end{abstract}

Keywords: metal-matrix coatings, tungsten carbide, electric spark deposition, wear, oxidation resistance.

УДК: $621.762 ; 537.523 .4$

\section{Упрочнение FeCrMoWCBSi аморфных электроискровых покрытий карбидом вольфрама}

\author{
Бурков А. А., Кулик М.А. ${ }^{\dagger}$ \\ Институт материаловедения Хабаровского научного центра ДО РАН (ИМ ХНЦ ДВО РАН), Хабаровск, 680042, Россия
}

\begin{abstract}
Новым направлением развития металломатричных покрытий являются композиты на основе аморфной матрицы с армирующими керамическими добавками. В настоящей работе были приготовлены композиционные покрытия методом электроискровой обработки стали 45 в смеси железных гранул с многокомпонентным составом CrMoWCBSi и добавлением порошка карбида вольфрама. По данным рентгенофазового анализа, с ростом концентрации WC в смеси гранул до 1.2 об. \% повышалось содержание фазы WC в составе покрытий. Кроме того, на рентгеновских дифрактограммах наблюдался металлический вольфрам, который являлся продуктом частичного растворения зерен WC в расплаве железа. В микроструктуре покрытий наблюдались включения карбида вольфрама средним диаметром $1.8 \pm 0.9$ мкм. Жаростойкость покрытий при температуре $700^{\circ} \mathrm{C}$ монотонно снижалась с ростом добавки WC в смеси гранул. Микротвердость покрытий с карбидом вольфрама находилась в диапазоне от 814 до $1118 \mathrm{HV}$, что выше по сравнению с полностью аморфным образцом (743 HV). Средние значения коэффициента трения покрытий с WC находились в диапазоне от 0.60 до 0.67, что на $30 \%$ ниже, чем у аморфного покрытия. Интенсивность изнашивания покрытий с карбидом вольфрама находилась в диапазоне $0.5-1.1 \times 10^{-5} \mathrm{Mм}^{3} / \mathrm{Hм}$, что ниже, чем у образца без WC $\left(1.8 \times 10^{-5} \mathrm{~mm}^{3} / \mathrm{Hм}\right)$. Оптимальная величина добавки порошка WC в смеси гранул, при осаждении покрытий для триботехнических применений составляет 1.2 об.\%. Таким образом, применение аморфных покрытий, армированных карбидом вольфрама, позволяет снизить износ стали 45 до 8 раз.
\end{abstract}

Ключевые слова: металломатричные покрытия, карбид вольфрама, электроискровое легирование, износ, жаростойкость. 


\section{1. Введение}

Композиты с металлической матрицей, армированные неметаллическими частицами, сочетают в себе свойства металлов (высокая пластичность и ударная вязкость) с керамикой (высокие прочность и модуль упругости). Они широко используется в механических деталях, подверженных абразивному воздействию [1]. Частицы карбида вольфрама обладают хорошими физическими свойствами, такими как высокая температура плавления, высокая твердость, стабильность и хорошая смачиваемость, поэтому их часто используют в качестве армирующей фазы [2]. В качестве материала матрицы, обычно используют сплавы на основе железа, никеля и кобальта [3-5]. Покрытия на основе Fe подходят для упрочнения и восстановления большинства формованных деталей и стоят недорого.

Покрытия с аморфной матрицей на основе железа демонстрируют множество превосходных свойств, таких как высокая твердость, высокая прочность на разрыв, хорошая износостойкость, коррозионная стойкость и жаростойкость [6,7]. Для нанесения аморфных покрытий хорошо подходит метод электроискрового легирования (ЭИЛ) [8]. Он позволяет локально упрочнить, защитить от коррозии, восстановить и отремонтировать поверхность металлических деталей, чтобы продлить срок их службы или использовать повторно [9-11]. ЭИЛ основано на явлении электрической эрозии анода и переносе этого материала на катод в условиях протекания микродуговых электрических разрядов. Это обеспечивает высокую адгезию покрытия и малый размер зоны термического влияния на подложке $[12,10]$. В наших предшествующих работах была показана возможность одностадийного формирования аморфных покрытий технологией электроискровой обработки в среде гранул, состоящих из разных компонентов [13], и внесением аморфизирующегося порошка [14]. В этом способе многокомпонентный порошок плавился и перемешивался с железом подложки в ходе электрических разрядов, и благодаря высоким скоростям охлаждения материала после прекращения разряда, происходило формирование аморфной фазы непосредственно в процессе нанесения покрытия. В данной работе исследовались условия армирования аморфного покрытия карбидом вольфрама, а также структура, жаростойкость и триботехнические свойства покрытий, приготовленных электроискровой обработкой стали 45 в смеси железных гранул и аморфизирующегося порошка с добавлением частиц WC.

\section{2. Материалы и методы исследования}

Покрытия осаждались на подложку из стали 45, в форме цилиндра диаметром 12 мм и высотой 10 мм. Исходная сталь 45 после заводской прокатки имела ферритоперлитную структуру со средним размером ферритных зерен 50 мкм. В качестве анодного материала использовались четыре смеси из гранул стали Ст. 3, аморфизирующегося многокомпонентного порошка и карбида вольфрама в различных соотношениях (Табл. 1). Много- компонентный порошок, состава: Cr 20; Мо 10; W 10; C 24; В 21; Si 15 ат.\%, был приготовлен смешиванием порошков хрома, молибдена, вольфрама, графита, кремния и тетраборида кремния в шаровой мельнице РМ 400 в течение 4 часов в спирте при скорости вращения 250 об/мин. По данным сорбтометра Sorbi-M шихта имела средний размер частиц 0.3 мкм. Порошок WC (ТУ 6-09-03-360-78) состоял из частиц диаметром $1.1 \pm 0.3$ мкм. Исходные порошки имели чистоту не менее 99.5 вес.\%. Схема установки для ЭИЛ в среде гранул подробно описана в [14]. Гранулы изготавливались путем нарезания проволоки из стали Ст. 3 диаметром $4 \pm 0.5$ мм на цилиндры длиной $4 \pm 1$ мм. Генератор разрядных импульсов IMES-40 вырабатывал импульсы тока прямоугольной формы амплитудой 110 А при напряжении 30 В, длительностью 100 мкс с частотой 1 кГц. В рабочий объем контейнера подавался защитный газ - аргон со скоростью 10 л мин $^{-1}$ для предотвращения окисления и азотирования поверхности образцов.

Фазовый состав и структура покрытий исследовались с применением рентгеновского дифрактометра ДРОН-7 в $\mathrm{Cu}-\mathrm{Ka}$ излучении и растрового электронного микроскопа (СЭМ) Sigma 300 VP, оснащенного микрорентгеноспектральным (MPC) анализатором INCA Energy. Износостойкость покрытий исследовалась по стандарту ASTM G99-17 при сухом трении скольжения с применением контртела в виде диска из быстрорежущей стали P6M5 на скорости $0.47 \mathrm{Mc}^{-1}$ при нагрузке $25 \mathrm{H}$. Износ образцов измеряли гравиметрическим способом с точностью 0.1 мг и рассчитывали интенсивность изнашивания по формуле: $W=\Delta m /(\rho P l)$, где $\Delta m-$ потеря массы образца при истирании; $\rho-$ плотность покрытия, которая принималась равной плотности стали $45 ; P-$ нагрузка и $l-$ длина пути трения. Коэффициент трения был измерен в процессе испытания на износ с использованием бесконтактного динамического датчика момента вращения M 40-50. Испытания на жаростойкость проводили в печи при температуре $700^{\circ} \mathrm{C}$ на воздухе. Образцы выдерживали при заданной температуре в течение $\approx 6$ ч., затем удаляли и охлаждали в эксикаторе до комнатной температуры. Во время испытания образцы помещались в корундовый тигель для учета массы отслоившихся оксидов. Общее время тестирования составляло 100 часов. Изменение массы всех образцов измеряли с использованием лабораторных весов с чувствительностью 0.1 мг.

Табл. 1. Концентрация карбида вольфрама в анодной смеси и обозначение покрытий.

Table 1. Tungsten carbide concentration in the anode mixture and designation of coatings.

\begin{tabular}{|c|c|c|c|c|}
\hline $\begin{array}{c}\text { Наименование образцов } \\
\text { Name of samples }\end{array}$ & W0 & W0.6 & W 1.2 & W1.8 \\
\hline $\begin{array}{c}\text { Концентрация WC, об.\% } \\
\text { WC concentration, vol.\% }\end{array}$ & 0 & 0.6 & 1.2 & 1.8 \\
\hline $\begin{array}{c}\text { Концентрация многокомпонентной } \\
\text { шихты, об.\% } \\
\text { Concentration of multicomponent } \\
\text { charge, vol.\% }\end{array}$ & 9 & 8.4 & 7.8 & 7.2 \\
\hline
\end{tabular}




\section{3. Результаты и обсуждение}

Рентгенофазовый анализ показал присутствие острых Брегговских рефлексов карбида вольфрама, вольфрама и железа подложки (Рис. 1). Концентрация карбида вольфрама в составе покрытий с ростом добавки порошка WC в анодной смеси увеличивалась немонотонно (Табл. 2). Снижение концентрации карбида вольфрама в покрытии при увеличении добавки WC выше 1.2 об.\% может объясняться ухудшением условий возникновения разрядов и снижением их количества из-за переизбытка порошка. Максимальная концентрация фазы WC в покрытии достигала 63 об.\%, что практически недостижимо для ЭИЛ стали 45 стандартными электродами системы WC-Со по причине высокой активности расплавленного железа к обезуглероживанию карбида вольфрама [15]. В данном случае, сохранение фазы WC в покрытии объясняется присутствием графита в порошке МСП, который насыщает железо углеродом, снижая его активность к обезуглероживанию WC [16]. Тем не менее часть карбида вольфрама подвергалась декарбидизации с образованием вольфрама, что можно описать уравнением реакции (1):

$$
\mathrm{WC}+3 \mathrm{Fe}=\mathrm{W}+\mathrm{Fe}_{3} \mathrm{C}
$$

В сечении покрытия W1.2 наблюдались светлые включения со средним диаметром $1.8 \pm 0.9$ мкм, которые представляют собой агломераты зерен карбида вольфрама (Рис. 2b). Удельный объем этих включений значительно ниже, чем демонстрируют данные рентгенофазового анализа. Это объясняется, тем, что значительный объем покрытия занимает аморфная фаза. Концентрация железа в составе покрытия находилась на уровне 55 - 60 ат.\%, тогда как содержание остальных элементов в среднем составляло от 3 до 4.5 ат.\%.

На Рис. 3 показана динамика изменения массы образцов с покрытиями при температуре $700^{\circ} \mathrm{C}$. Привес образцов обусловлен фиксацией кислорода на поверхности образцов в виде оксида железа в модификации гематита $\mathrm{Fe}_{2} \mathrm{O}_{3}$. Жаростойкость покрытий за 100 часов циклических испытаний была от 6.5 до 12.5 раз выше, по сравнению со сталью 45 без покрытия. Лучшую стойкость

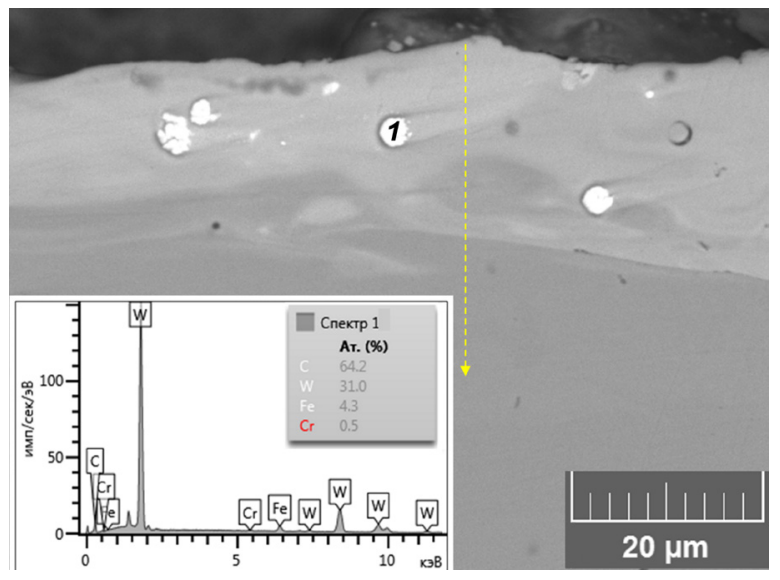

a к высокотемпературному окислению продемонстрировало полностью аморфное покрытие. Характерно, что с ростом содержания армирующей добавки, жаростойкость покрытий постепенно снижалась. Это объясняется тем, что карбид вольфрама начинает окисляться при температуре выше $600^{\circ} \mathrm{C}$, формируя рыхлый оксид $\mathrm{WO}_{3}$ [17]. Это открывает каналы для проникновения кислорода сквозь жаростойкое аморфное покрытие к стальной подложке. Вместе с тем, двукратное снижение жаростойкости в случае образца W1.8 показывает, что объемная доля зерен WC в его составе примерно равна

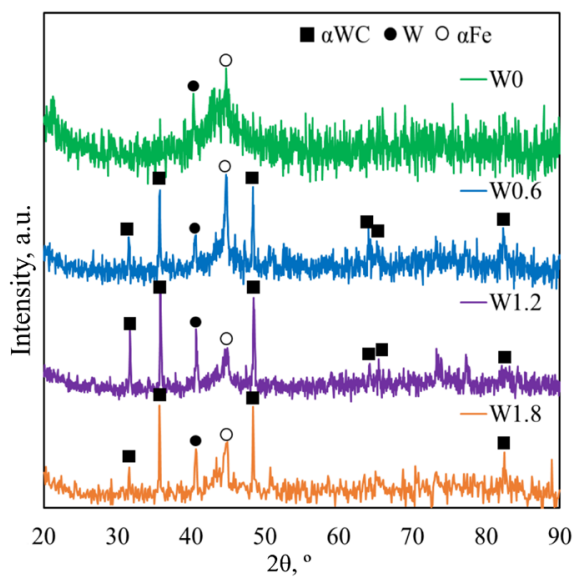

Puc. 1. (Color online) Рентгеновские дифрактограммы осажденных покрытий.

Fig. 1. (Color online) X-ray diffraction patterns of the deposited coatings.

Табл. 2. Соотношение кристаллических фаз в покрытиях по результатам полуколичественного рентгенофазового анализа.

Table 2. The ratio of crystalline phases in coatings according to the results of semi-quantitative $\mathrm{X}$-ray phase analysis.

\begin{tabular}{|c|c|c|c|}
\hline \multirow{2}{*}{$\begin{array}{c}\text { Образцы } \\
\text { Samples }\end{array}$} & \multicolumn{3}{|c|}{$\begin{array}{c}\text { Содержание фаз, об.\% } \\
\text { Phase content, vol.\% }\end{array}$} \\
\cline { 2 - 4 } & $\mathrm{Fe}$ & $\mathrm{WC}$ & $\mathrm{W}$ \\
\hline $\mathrm{W} 0.6$ & 45.8 & 39.55 & 14.6 \\
\hline $\mathrm{W} 1.2$ & 15.3 & 63.1 & 21.6 \\
\hline $\mathrm{W} 1.8$ & 26 & 48.8 & 25.2 \\
\hline
\end{tabular}

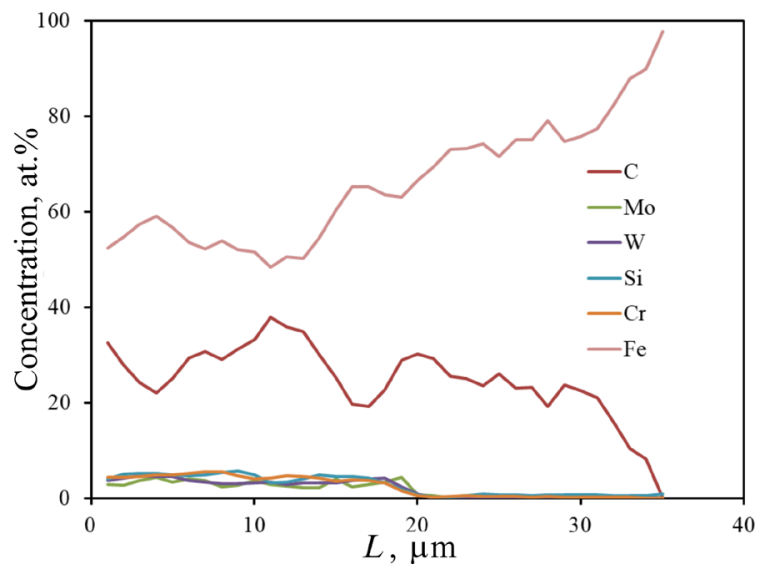

$\mathrm{b}$

Pис. 2. (Color online) СЭМ изображение покрытия W1.2 и ЭДС спектр точки 1 (a), распределение элементов по глубине (b). Fig. 2. (Color online) SEM image of coating W1.2 and EDS spectrum of point 1 (a), distribution of elements in depth (b). 


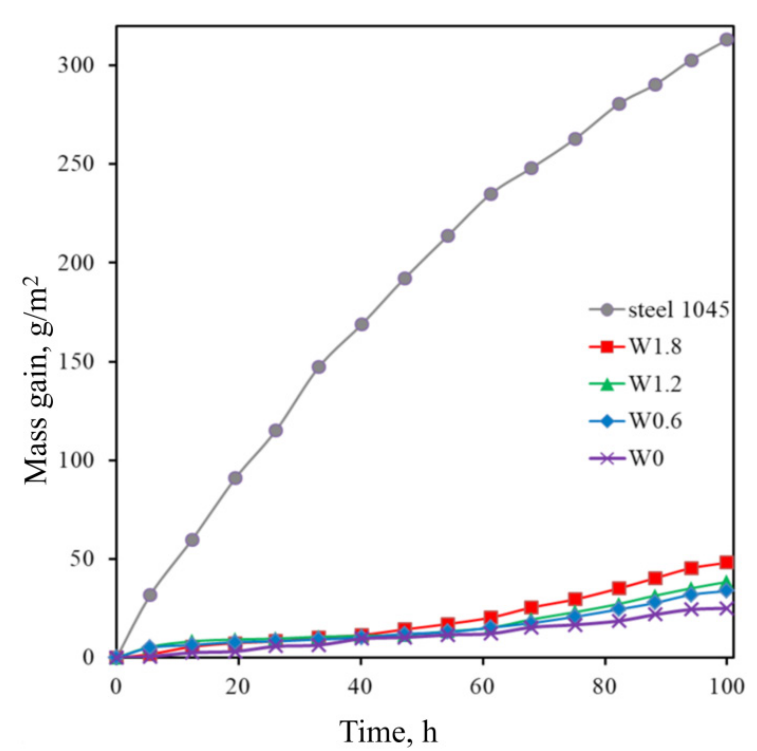

Pис. 3. (Color online) Жаростойкость покрытий при температуре $700^{\circ} \mathrm{C}$ по сравнению со сталью 45 и полностью аморфным покрытием.

Fig. 3. (Color online) Oxidation resistance of coatings at a temperature of $700^{\circ} \mathrm{C}$ in comparison with AISI 1045 and completely amorphous coating.

доле дефектов, таких как открытые поры и трещины, в исходном аморфном покрытии W0.

Средняя микротвердость покрытий с карбидом вольфрама находилась в диапазоне от 814 до $1118 \mathrm{HV}$ с максимумом у образца W1.2, тогда как для аморфного образца W0 она составляла 743 HV (Рис. 4a). Таким образом, армирование аморфных покрытий карбидом вольфрама позволяет повысить их твердость до полутора раз. Снижение твердости покрытий для образца W 1.8 объясняется более низкой концентрацией карбида вольфрама в его составе, по сравнению с W1.2. Применение аморфных покрытий с карбидом вольфрама позволяет повысить твердость поверхности стали 45 в семь раз. Кинетика изменения коэффициента трения образцов при испытании на износ в режиме сухого скольжения показана на Рис. 4b. Средние значения коэффициента

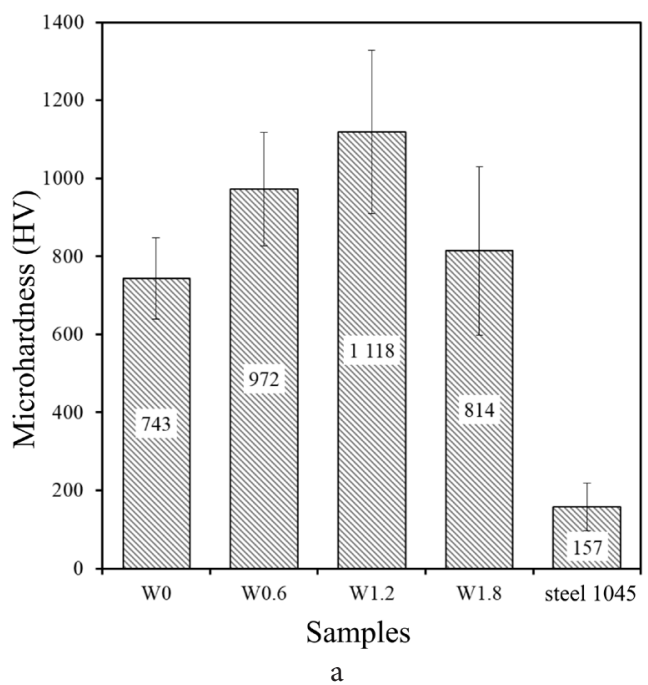

трения покрытий с WC находились в диапазоне от 0.60 до 0.67 , что ниже, чем у полностью аморфного покрытия и стали 45 примерно на 30\%. Наиболее низкие значения коэффициента трения наблюдались у образца W1.2. В случае стали без покрытия на кривых коэффициента трения наблюдался высокий уровень шума, который объясняется периодическим формированием и разрушением трибооксидного слоя [18-19].

Результаты испытания покрытий на износ в режиме сухого скольжения показали, что интенсивность изнашивания находилась в диапазоне $0.5-1.1 \times 10^{-5} \mathrm{Mм}^{3} / \mathrm{Hм}$, что ниже, чем у стали 45 от 4 до 8 раз. (Рис. 5 a). Износ аморфного образца W0 был в 3.6 раз выше, чем у наиболее износостойкого образца W1.2. Таким образом, оптимальная величина добавки порошка WC в смеси гранул, при осаждении покрытий для триботехнических применений составляет 1.2 об.\%. В целом, поведение износа исследуемых аморфных покрытий хорошо согласуется с данными по микротвердости и коэффициенту трения (Рис. 4). Для трибологических взаимодействий только интенсивность износа и коэффициент трения являются двумя общими параметрами, которые в отличие от твердости, вязкости, модуля упругости и т.д., не являются неотъемлемыми свойствами материалов. Скорость износа и коэффициент трения изменяются во времени с учетом множества факторов: материала пар трения, скорости скольжения, приложенных нагрузок и условий окружающей среды. На Рис. 5b показано монотонное снижение интенсивности изнашивания и коэффициента трения с ростом твердости покрытий. Это хорошо согласуется с теорией Архарда [20]:

$$
V_{w}=k \frac{P l}{H},
$$

где $V_{w}$ - объем материала, удаляемого изнашиванием, $H$ - твердость материала, $k-$ коэффициент износа, $P-$ нормальная нагрузка и $l-$ путь трения. Таким образом, армирование аморфного покрытия карбидом вольфрама повышает его твердость и снижает коэффициент трения, что в совокупности приводит к повышению его износостойкости.

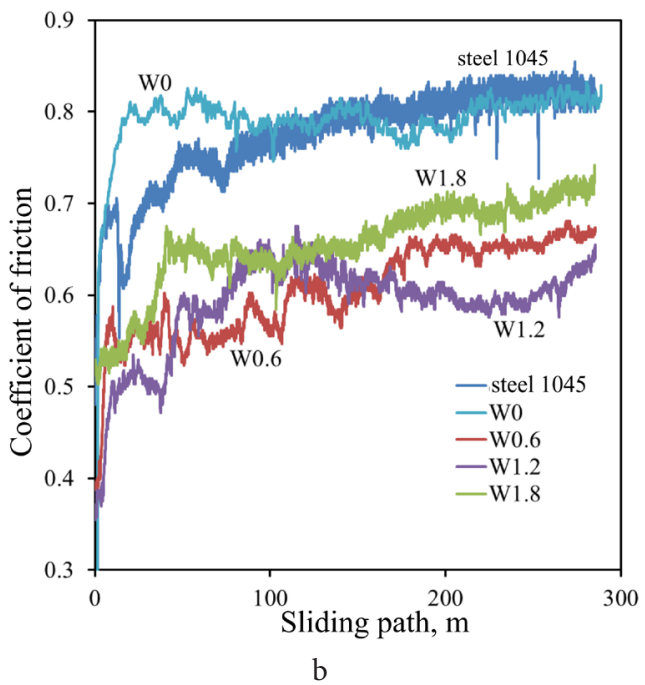

Pис. 4. (Color online) Микротвердость (а) и коэффициент трения (b) покрытий по сравнению со сталью 45.

Fig. 4. (Color online) Microhardness (a) and coefficient of friction (b) of coatings in comparison with AISI 1045. 


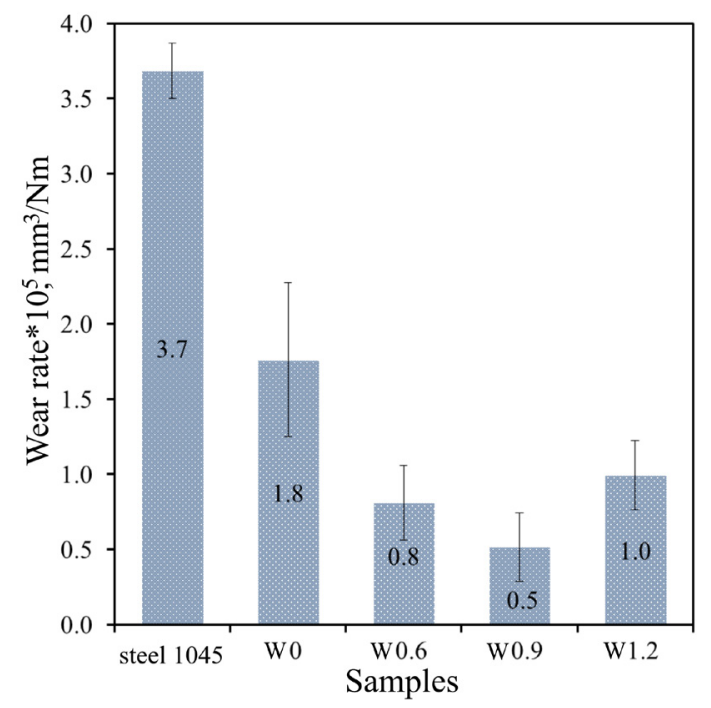

a

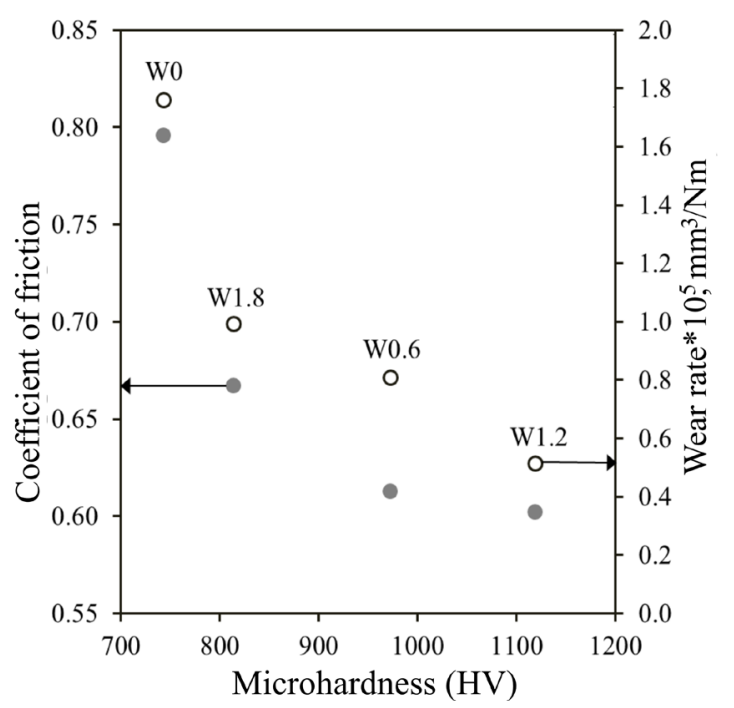

$\mathrm{b}$

Рис. 5. Интенсивность износа покрытий по сравнению со сталью 45 (а) и зависимость коэффициента трения и интенсивности изнашивания от твердости покрытий (b).

Fig. 5. Intensity of wear of coatings in comparison with AISI 1045 (a) and dependence of the coefficient of friction and intensity of wear on the hardness of coatings (b).

\section{4. Выводы}

1. Добавление карбида вольфрама к смеси железных гранул с аморфизирующимся порошком при электроискровой обработке стали 45 , приводит к получению металлокерамических покрытий. В микроструктуре покрытия наблюдались зерна WC, внедренные в матрицу, состоящую из аморфной фазы, вольфрама и железа. Металлический вольфрам образуется в результате обезуглероживания карбида вольфрама при взаимодействии с расплавом железа. С ростом добавки WC от 0.6 до 1.2 об.\% повышалась концентрация карбида вольфрама в покрытии.

2. Жаростойкость покрытий была от 6.5 до 12.5 раз выше по сравнению со сталью 45 за 100 часов испытаний. С ростом добавки карбида вольфрама жаростойкость образцов монотонно снижалась.

3. Армирование аморфного покрытия карбидом вольфрама повышает его микротвердость с 743 до $1118 \mathrm{HV}$, снижает коэффициент трения до $30 \%$ и улучшает износостойкость в 3.6 раза. Лучшие триботехнические свойства продемонстрировало покрытие с добавкой 1.2 об.\% карбида вольфрама.

\section{Литература/References}

1. S. W. Huang, D. Nolan, M. Brandt. Surf. Coat. Technol. 165, 26 (2003). Crossref

2. Y. Shi, X. Du, P. Zhuang, H. Zhang. Materials Research Express. 6, 1165h7 (2019). Crossref

3. L. Fan, Y. Dong, H. Chen, L. Dong, Y. Yin. Journal Wuhan University of Technology, Materials Science Edition. 34 (2), 433 (2019). Crossref

4. P. Vespa, P. T. Pinard, R. Gauvin, M. Brochu. J. Mater. Eng. Perform. 21, 865 (2012). Crossref

5. M. Afzal, A. Nusair Khan, T. Ben Mahmud, T.I. Khan, M. Ajmal. Surf. Coat. Technol. 266, 22 (2015). $\underline{\text { Crossref }}$
6. S. Zhou, Y. Xu, B. Liao, Y. Sun, X. Dai, J. Yang, Z. Li. Optics and Laser Technology. 103, 8 (2018). Crossref

7. A.A. Burkov, P.G. Chigrin. Surface and Coatings Technology. 351, 68 (2018). Crossref

8. M.F. Hasanabadi, F.M. Ghaini, M. Ebrahimnia, H. R. Shahverdi. Surface and Coatings Technology. 270, 95 (2015). Crossref

9. B. Antoszewski, O.P. Gaponova, V.B. Tarelnyk, O.M. Myslyvchenko, P. Kurp, T.I. Zhylenko, I. Konoplianchenko. Materials. 14, 739 (2021). Crossref

10. D. Wang, J. Gao, R. Zhang, S. Deng, S. Jiang, D. Cheng, P. Liu, Z. Xiong, W. Wang. Surface and Coatings Technology. 408, 126851 (2021). Crossref

11. S. Peterkin, N. Scotchmer, Z. Jiao. Welding Journal. 98 (12), 33 (2019).

12. M. Roostaei, H. Aghajani, M. Abbasi, B. Abasht. Ceramics International. 47 (8), 11644 (2021). Crossref

13. A. A. Burkov, S.A. Pyachin, M. A. Ermakov, A. V. Syuy. Journal of Materials Engineering and Performance. 26, 901 (2017). Crossref

14. A.A. Burkov. Obrabotka metallov (tekhnologiya, oborudovanie, instrumenty) $=$ Metal Working and Material Science. 21,19 (2019). (in Russian) [А.А. Бурков. Обработка металлов (технология, оборудование, инструменты). 21,19 (2019).] Crossref

15. A. A. Burkov, S. A. Pyachin. Solid State Phenomena. 213, 131 (2014). Crossref

16. A. A. Burkov, S. A. Pyachin. Journal of Materials Engineering and Performance. 23 (6), 2034 (2014). Crossref

17. M. Jafari, M. H. Enayati, M. Salehi, S. M. Nahvi, J.C. Han, C. G. Park. Surface and Coatings Technology. 302, 426 (2016). Crossref

18. F. H. Stott, M. P. Jordan. Wear. 250, 391 (2001). Crossref

19. M.X. Wei, S. Q. Wang, L. Wang, X. H. Cui. Tribology Transactions. 54, 840 (2011). Crossref

20. J.F. Archard. Journal of Applied Physics. 24, 981 (1953). $\underline{\text { Crossref }}$ 